\title{
The Influence of Executive Function on Prospective Memory in Word- and Category-Based Tasks
}

\author{
So Yeon Park ${ }^{1}$, Hana Song ${ }^{2}$ \\ M. A., Department of Child Psychology and Education, Sungkyunkwan University, Seoul, Korea ${ }^{1}$ \\ Professor, Department of Child Psychology and Education, Sungkyunkwan University, Seoul, Korea ${ }^{2}$ \\ 유아의 실행기능이 단어형 미래계획기억 과제와 \\ 범주형 미래계획기억 과제 수행에 미치는 영향 \\ 박소연 ${ }^{1}$, 송하나 ${ }^{2}$ \\ 성균관대학교 아동·청소년학과 석사 ${ }^{1}$, 성균관대학교 아동·청소년학과 교수 ${ }^{2}$
}

\begin{abstract}
Objectives: This study aimed to investigate the influence of executive function on the development of prospective memory in young children.

Methods: The participants of this study included 47 preschool children aged 4 and 5 years. Children completed word- and category-based tasks that measured prospective memory. The following tasks were also used to assess executive function in children: Flanker, day/night, backward digit span, and dimensional change card sort tasks.

Results: The inhibitory control and working memory of children significantly predicted prospective memory measured by the word-based task. Inhibition particularly accounted for prospective memory in the category-based task.

Conclusion: The findings demonstrated the influence of the components of executive function on the prospective memory of young children in the preoperational period.
\end{abstract}

Keywords: prospective memory, executive function, inhibition, working memory, shifting

\section{Introduction}

최근 유아기에 발달하는 미래계획기억에 대한 관심이 증가 하고 있다. 기억이 과거의 경험을 회상하는 것이라고 정의해 왔던 이전의 연구들과는 달리 최근 신경과학 연구들을 통해 아주 어린 시기부터 과거, 현재, 미래의 기억이 경험이나 시 간적 순서에 관계없이 발달한다고 보고되고 있다(Josselyn \& Frankland, 2012). 미래계획기억은 미래에 특정한 시간이 되거 나 사건 단서가 나타났을 때 수행하기로 의도한 행동을 하는 것을 말한다(Ellis \& Kvavilashvili, 2000). 앞서 언급한대로 미래 계획기억은 기억이 과거의 일을 회상하는 것이라는 통념에서

Corresponding Author: Hana Song, Professor, Department of Child Psychology and Education, Sungkyunkwan University, 25-2, Sungkyunkwanro, Jongnogu, Seoul, Korea

E-mail: jni4ever@skku.edu
벗어나 아직 일어나지 않은 사건 역시 기억의 일부라는 것을 강조하고 있으며(Einstein \& McDaniel, 1990), 실제로 심부름 을 가거나 약을 시간에 맞춰 복용하는 등 일상생활과 깊은 관 련이 있다.

미래계획기억은 크게 사건을 기반으로 한 것과 시간을 기 반으로 한 것으로 나뉘는데(Einstein \& McDaniel, 1990), 사건 기반 기억은 특정한 외부의 단서 혹은 사건이 있을 때 수행하 거나 일어나야 할 일들을 기억하는 것이고, 시간 기반 기억은 일정한 시간이 흐르거나 적절한 때가 되었을 때 해야 할 행동 을 기억하는 것이다. 유아기는 시간 읽기와 측정 등 시간 개념 의 발달이 충분히 이루어지지 않는 시기이다. 이에 비해, 일화

(C)The Korean Association of Child Studies

This is an Open Access article distributed under the terms of the Creative Commons Attribution Non-Commercial License (http:// creativecommons.org/licenses/by-nc/4.0) which permits unrestricted noncommercial use, distribution, and reproduction in any medium, provided the original work is properly cited. 
형태의 사건 기반 기억은 어린 유아들에게 친숙한 기억이기 때문에(Sutherland, Pipe, Schick, Murray, \& Gobbo, 2003) 측정 이 용이한 면이 있다. 이러한 측정의 용이성과 발달적 적합성 에 기반하여, 본 연구에서는 사건 기반 과제를 사용하여 유아 기 동안 미래계획기억이 어떻게 발달하는지 검증하려 하였다.

미래계획기억 발달에 대한 선행 연구들에서, 유아를 다 룬 연구들(Ślusarczyk, Niedźwieńska, Białecka-Pikul, 2018; Somerville, Wellman, \& Cultice, 1983)을 살펴보면, 만 2세의 유 아들이 대부분 미래계획기억 수행에 실패하였지만, 친숙하고 흥미 있는 과제를 제시하면 수행이 가능한 것으로 나타났다. Kliegel과 Jäger (2007)는 만 2-6세 유아들을 대상으로 그림 카 드를 명명하다가 사과 카드가 나오면 박스 아래에 카드를 숨 기는 과제를 사용하여 사건 기반 미래계획기억을 측정하였다. 그 결과 만 3 세부터 단서를 바탕으로 한 미래계획기억 과제 수 행 능력이 점차 발달한다고 보고하였다. 이러한 연구들은 미 래계획기억이 영유아기 동안 발달한다는 것을 보여준다.

그러나 만 4세 이상은 되어야 간섭이 일어나거나 혹은 기 억해야 할 단서의 개수가 여러 가지인 복잡한 형태의 미래계 획기억 과제를 수행하는 것이 가능하였으며, 아동기까지 연령 이 증가할수록 능숙하게 수행하는 것으로 나타났다(Leigh \& Marcovitch, 2014). 즉, 미래에 수행해야 할 내용을 기억하는 것 에 방해가 되는 관련 없는 자극을 제시하는 간섭 상황에서 더 어린 유아들은 주의가 더욱 쉽게 흐트러져 수행을 제대로 이 행하지 못할 수 있다. 따라서 Leigh와 Marcovitch (2014)를 비 롯한 여러 연구자들(Ford, Driscoll, Shum, \& Macaulay, 2012; Walsh, Martin, \& Courage, 2014)은 복잡한 형태의 미래계획 기억이 만 4세 이후에 점진적으로 발달한다고 보고하고 있 다. 한편, 일상적인 기억에 결함이 있는지 측정하는 Rivermead Behavior Memory Test (RBMT)를 사용한 Seo와 Choi (2004)의 연구에서는 연령차가 유의하게 나타나지 않았다. Seo와 Choi (2004)는 RBMT의 9개 하위 검사 중 수정된 형태의 약속 검사 를 사용하여 사건 기반 미래계획기억을 측정하였는데, 이 검 사는 유아가 퍼즐 놀이를 하는 동안 알람 소리가 울리면 퍼즐 을 멈추고 실험자와 어떤 주제에 대해 말하기로 약속한 것을 이행하는 것이었다. 그 결과, 만 3-5세 사이에 발달적 변화가 유의하지 않음을 보고하였다. 이와 같이 선행 연구들마다 다 루고 있는 유아의 연령 범위에 따라 결과가 조금씩 다르게 나 타나기도 한다. 그러나 단순 회상이 아닌 간섭이 들어간 복잡 한 형태의 미래계획기억 회상이 4세 전후로 나타난다는 것에 는 일반적으로 동의하는 것으로 보인다.

선행 연구들이 보고한 다양한 연령차는 각 연구에서 사용
한 과제의 차이와 더불어 유아기의 발달적 특성이 영향을 미 쳤을 가능성이 있다. 유아기는 Piaget의 전조작기에 해당하는 시기로 표상의 발달이 현저하게 일어나는 시기이다(Carlson, 2005). 이와 함께 언어 능력 역시 발달한다. 그러나 이 시기에 는 구체적 조작기에 나타나는 보존, 분류, 순서, 추론 등의 능 력이 아직 완전히 발달하지 않았기 때문에 직관적이고 비논리 적인 사고를 하는 경향이 있다. 또한 사물의 여러 특성 중에서 도 눈에 띄는 하나의 특성만 고려하는 중심화 경향성이 강하 다(Smidts, Jacobs, \& Anderson, 2004).

이처럼 Piaget의 이론에 따라 유아들이 전조작기의 특성만 보유하고 있다면, 여러 가지 지각적 특성을 파악하고 통찰해 야 하는 과제보다 색이나 모양 등 한 가지 특성에만 집중하는 과제를 더욱 수월하게 수행할 것이다. 이와 유사하게, 유아들 은 사물의 이름, 그것이 속하는 상위 범주 등 여러 특성을 파악 해야 하는 과제보다 사물의 이름에만 집중하는 과제를 더욱 능숙하게 수행할 것이다. 특히 유아기는 사물에 대한 표상과 개념의 이해가 현저하게 발달하는 시기이므로 단어를 중심으 로 한 사건 기반 미래계획기억 과제는 유아들이 충분히 수행 가능할 것으로 예상된다.

그러나, 단순한 사물의 표상이 아닌 유목이나 분류의 상위 개념을 유아들이 이해하기에는 아직 미숙한 상태이다(Winer, 1980). 유아들은 단일 개념들 간의 관계나 위계를 파악하면 서 점차 상위 범주를 획득하기 때문에(Clark \& Johnson, 1994; Lucariello, Kyratzis, \& Nelson, 1992), 예를 들어, 바지, 치마, 코트 등의 구체적인 사물의 개념을 '옷’이라는 상위 범주보다 더 정확하게 이해한다. 따라서 유목 분류 같은 요소가 들어간 기억 과제를 사용하였을 때에는 단순 개념 이해 과제를 사용 하였을 때와 다른 결과가 나타날 수 있다. 또한 기억은 인지 적 자원이나 용량이라는 부분이 관여한다. 사물 이름을 회상 하는 것 같은 단순한 기억 과제와는 달리, 개별 사물들이 상 위 범주에 포함되는지의 여부를 결정하는 경우에는 인지적 용량이 더 요구되기 때문에 유아의 수행이 영향을 받을 수 있 을 것이다. 더욱이 전조작기 유아들이 사물의 한 가지 특성에 주목하는 경향이 있다는 것을 고려할 때, 눈에 보이는 사물의 이름이 아닌 유목을 떠올리는 과제의 난이도가 더 높다. 이처 럼 직관적 사고에 영향을 받는 유아의 전조작적 특성이 미래 계획기억 과제 수행에 영향을 줄 수 있을 것으로 생각하여 본 연구에서 이를 확인하고자 하였다. 무엇보다, Piaget 이론과는 반대로, Lourenço와 Machado (1996)는 5, 6세경의 유아들도 인과적 논리의 이해나 순서적 추리가 가능하다고 하였다. 이 에 본 연구에서는, 단일 개념과 유목 분류가 들어간 미래계획 
기억 과제들을 각각 제시하여 유아의 과제별 수행을 살펴보 고자 하였다.

한편, 미래계획기억을 뇌신경학적 관점에서 탐구한 선 행 연구들은 미래계획기억의 요소로 볼 수 있는 복합처리 (McDaniel \& Einstein, 2000)와 주의를 기반으로 한 전략적인 모니터링(Smith, 2003)에 대해 언급하였다. 복합처리 관점은 미래계획기억을 수행할 때 전략적인 모니터링(top-down)뿐 만 아니라, 환경적인 단서에 의해 미래계획기억이 자동적으로 인출(bottom-up)되는 과정이 복합적으로 관여한다는 것이다. 즉, 이 연구들에서는 미래계획기억 수행에서 주로 전전두피질 영역이 활성화되었는데, 활성화된 부분들은 실행기능의 영역 과 중복되는 영역이 많았다(Friedman \& Miyake, 2017).

실행기능이란 목표를 달성하기 위해 사고와 감정 그리고 행동을 감시하고 조절하는 관리책임자 역할을 하는 인지적 기 제로 정의된다(Diamond, 2013). Miyake 등(2000)은 억제, 작업 기억, 전환을 실행기능의 세 주요 요인으로 제안하였다. 억제 는 우세하지만 적절하지 않은 반응을 의도적으로 통제하는 능 력이며, 작업기억은 정보처리 능력으로 과제와 관련된 정보를 모니터링 하고 조작하는 능력을 의미한다. 작업기억은 주의와 용량을 조절하여 억제의 처리와 상호 연관된다고 알려져 있다 (Gomez, Gomez, Winther, \& Vance, 2014). 또한 인지적 유연성 이라고도 불리는 전환은 주의나 사고를 유연하게 조작하여 과 제에 새로운 규칙을 적용하거나 작업을 변환할 때 요구되는 능력이다(Bjorklund, \& Causey, 2017; Carlson, 2003).

이 세 가지 요인은 전대상피질이 발달하는 영유아기에 현 저히 발달한다고 알려져 있다. 하위 요인 중 억제는 우측 하 전두피질(Aron, Robbins, \& Poldrack, 2014), 작업기억은 배외 측 전전두피질과 밀접한 관련이 있으며(Barbey, Koenigs, \& Grafman, 2013), 전환 역시 전두 및 후두 피질의 활성화를 수 반하였다(C. Kim, Johnson, Cilles, \& Gold, 2011). 여기서 배외 측 전전두피질은 단서가 제시되었을 때 주의를 요하는 미래 계획기억 수행에서 주요하게 활성화되는 영역이다(McDaniel, LaMontagne, Beck, Scullin, \& Braver, 2013). 이처럼 피질 영역 의 중복은 기억 과제와 유사하게 실행기능에도 선택적 주의가 요구되며, 미래계획기억 과제 수행이 단순한 기억 회상을 기 반으로 하는 것이 아니라 단서에 따라 여러 가지 수행이 동시 에 활성화되어야하기 때문에 인지적 통제가 필요하다는 것을 시사한다. 즉, 뇌 활성화 영역을 통해 두 변인들의 관련성을 짐 작할 수 있다.

실행기능과 미래계획기억 간의 관계를 검정한 선행 연구 를 살펴보면, 학령기 아동과 초기 성인기를 대상으로 한 연구
에서 미래계획기억이 억제 및 작업기억과 관련이 있었지만 전 환과는 관련이 없었다(Mäntylä, Carelli, \& Forman, 2007). 또한 4-6세 유아를 대상으로 한 Mahy와 Moses (2011)의 연구에서 는 작업기억이 미래계획기억과 관련이 있는 반면에, 억제는 유의한 관련이 없다고 제시하였다. 반대로, 같은 연령의 유아 들을 대상으로 한 다른 연구들(Ford et al., 2012; Mahy, Moses, \& Kliegel, 2014)에서는 억제가 미래계획기억에 유의한 영향을 미쳤지만 작업기억은 유의한 영향을 미치지 않았다

이러한 현상은 실행기능 하위 요인인 작업기억, 억제, 전환 이 발달하는 시기의 차이에서 비롯된 것이 아닌가 생각된다. 예를 들면, 작업기억이 관여하는 주의와 용량의 조절은 망상 계가 발달하는 청소년기 전기까지 발달하기 때문에 다른 요인 보다 더 오래 더 천천히 발달하는 경향이 있고, 억제 기제는 이 보다는 좀 더 빠르게 유아기에서 아동기 초기까지 발달하는 것으로 알려져 있다(Best \& Miller, 2010; van't Wout, O’Donnell, $\&$ Jarrold, 2019). 그러나 실행기능 하위 요인들의 발달적 경향 만으로 미래계획기억이 영향을 받는 것인지 뚜렷한 결론을 내 리기에는 연구가 많지 않은 실정이다. 따라서, 유아를 대상으 로 실행기능이 미래계획기억에 어떠한 영향을 미치는지 다시 검증해 볼 필요가 있을 것이다.

종합하면, 본 연구에서는 유아들을 대상으로 미래계획기억 이 실행기능의 하위 요인인 억제, 작업기억, 전환에 어떠한 영 향을 받는지 알아보고자 하였다. 미래계획기억 수행이 가능 한 만 4, 5세 유아를 대상으로 과제의 속성에 따라 각각 어떠 한 영향을 미치는지 알아보았다. 앞서 언급한 대로, 주의와 용 량의 조절이 작업기억 등 실행기능의 하위 요인에 영향을 미 친다고 알려져 있기 때문에 인지적 용량과 난이도가 다르게 반영된 두 가지의 미래계획기억 과제를 사용하였다. 즉, 단순 표상을 기반으로 단어의 개념을 이해하였을 때 수행이 가능한 단어형 과제와 유목을 기반으로 하여 각 단어를 상위 범주로 분류할 수 있어야 수행이 가능한 범주형 과제로 나누어 연구 를 수행하였다. 본 연구의 연구문제는 다음과 같다.

\section{연구문제 1}

유아의 미래계획기억(단어형, 범주형)과 실행기능에서의 연 령차는 어떠한가?

\section{연구문제 2}

유아의 실행기능(억제, 작업기억, 전환)이 단어형 미래계획기 억 과제 수행에 미치는 영향은 어떠한가? 


\section{연구문제 3}

유아의 실행기능(억제, 작업기억, 전환)이 범주형 미래계획기 억 과제 수행에 미치는 영향은 어떠한가?

\section{Methods}

\section{연구대상}

본 연구는 만 4-5세 유아를 대상으로 진행하였다. 만 4세 전 후가 실행기능 발달의 민감기로 보고되고 있으며(Anderson, 2002; Carlson, 2005), 만 4-5세 유아가 다수의 미래계획기억 연 구에서 과제 수행이 가능한 것을 바탕으로 유아의 연령을 정 하였다. 경기도 지역의 2 개 유아교육 기관에 연구 참여 동의서 를 배부하였고, 동의서가 회수된 58명의 유아 중 결석이나 불 성실한 응답을 보인 사례를 제외하고 최종적으로 총 47명의 자료를 분석하였다. 연구 문제 분석을 위해 G*Power를 사용하 여 파워를 검정한 결과 예측변인이 3 개인 경우, 중간정도의 효 과크기에서 유의수준 .05와 파워 .95인 회귀분석을 위해서는 38 명의 피험자가 필요한 것으로 나타나 본 연구의 피험자 수 는 최소 기준치를 넘은 것으로 확인하였다. 47 명의 유아들은 평균 월령이 60.96개월 $(S D=6.09)$ 이었으며, 만 4세 유아는 25 명(평균 월령 55.96개월, $S D=2.33$ ), 만 5세 유아는 22명(평균 월령 66.65개월, $S D=3.38$ )이었다. 이 중 남아는 21명(44.7\%), 여아는 26명(55.3\%)이었다.

\section{연구도구}

\section{미래계획기억}

유아들의 미래계획기억을 측정하기 위해 Zhang, Zuber, Liu, Kliegel과 Wang (2017)의 도구를 참고하여 과제를 구성하였 다. 난이도에 따라 과제를 구분하기 위해 단어만 제시되는 과 제와 유목 분류가 들어가는 상위 과제를 구성하였다. 과제들 은 팬더를 등장인물로 제시하고 유아들에게 목표 단어(단순 표상) 또는 범주(상위 유목 표상)를 찾아 미래계획기억을 수 행하라고 지시하는 형태였다. 즉, 단어형은 '목표 단서+의도 된 행동', 범주형은 ‘목표 단서의 범주 인식+의도된 행동’으로 구성되었다. 상위 과제인 범주형 과제는 만 5세부터 16세까 지 사용 가능한 Kang (2003)의 언어기억검사와 아동을 대상 으로 우리말 범주를 조사한 Jeun과 Kang (2007)의 연구를 참
고하여 '동물' 범주로 정하였다. 일상에서 너무 친숙한 개, 고 양이 등을 제외하고 동물원에서 일반적으로 볼 수 있는 동물 6개를 선정하였다.

단어형 과제의 수행 조건으로 원도구의 "Got it."을 번역한 “찾았다.”를, 범주형 조건으로 이와 구별되게 “일어나.”를 외 치도록 하여 수행 조건에 중복과 간섭을 피하였다. 그러나 예 비실험결과 단어형 과제 수행에서 유아들이 집 그림이 나왔 을 때 찾았다가 아니라 “집 찾았다.”로 언급하는 경향이 나타 났다. 화면에 제시되는 그림의 이름을 명명하고 있던 것이 수 행에 영향을 준 것으로 생각된다. 이 과제가 유아의 통제기제 를 측정하는 것이 아니라 미래계획기억 단서와 의도된 행동을 기억하는 것이 주된 것이었으므로 이를 고려하여 본 실험에서 “집 찾았다.”를 사용하였다. 과제 수행에는 눈을 감고 있는 팬 더 인형과 노트북이 사용되었다.

단어형 과제 단어형 과제에서는 유아에게 친숙한 음식, 탈 것, 가구, 가전 범주의 그림 50 개를 사용하였다. 50 개의 그림 중 미래계획기억의 목표 단서인 집 그림은 총 6 장이었다. 예비 실험을 통해 유아들이 그림 제시 순서에 영향을 받는지 점검 하고, 최종적으로 Zhang, Ballhausen, Liu, Kliegel과 Wang (2019) 의 도구에서 제시된 방식에 따라 목표단서가 너무 떨어진 간 격으로 제시되지 않도록 7배수로 배치하였다. 유아들과 일대 일로 과제를 수행하였다.

유아들에게 팬더 인형을 보여주면서 "팬더가 오늘 중국에 서 왔고 집을 찾아주어야 한다.”고 하였다. 또한 팬더에게 한글 을 알려주기 위해 화면에 나오는 그림의 이름을 명명하다가 집 그림이 나오면 “집 찾았다!”라고 외쳐야한다고 설명하였다.

유아들에게 과정을 설명한 후 연습을 실시하였고 연습 시 행에서는 어휘 능력과 미래계획기억 수행을 명확히 구분하 기 위해, 유아가 집 그림을 보고 그냥 “집.”이라고 하면 “집 찾 았다!”라고 해야 한다고 수정해주었다. 연습 수행이 끝나고 본 수행에서 이러한 오류를 보이면 오답 처리 하였다.

본 과제는 유아의 어휘력을 측정하는 것이 아니었으므로 집 이외의 그림에 대한 명명은 점수화하지 않았다. 유아가 단 어형 과제의 수행에 성공하면 1점을 부여하였으며 총점의 범 위는 0-6점이었다. 본 연구에서 내적합치도(Cronbach's $\alpha$ )는 .96 이었다.

범주형 과제 범주형 과제에서는 유아들에게 친숙한 동물 범 주(목표 단서)를 상위 개념으로 선택하였다. 총 6 개의 동물 그 림(돼지, 호랑이, 말, 원숭이, 사자, 기린)을 포함한 50 개의 그 
림을 사용하였다. 나머지 44 개의 그림들은 단어형 과제와 중 복되지 않는 그림이었다.

범주형 미래계획기억 과제에서는 동물의 구체적인 이름을 명명하는 것이 아니라, 각각의 그림을 '동물’이라는 범주로 인 식할 수 있는지 알아보았다. 따라서 유아들에게 화면에 제시 되는 그림의 이름을 명명하다가 동물 그림이 나오면 팬더 인 형을 향해 “일어나.”라고 외쳐야 한다고 설명하여 유아들이 사자나 기린을 동물이라는 범주로 인식하고 기억할 수 있는지 알아보았다. 과제 시행 및 채점 방식은 단어형 과제와 동일하 게 진행하였고 최고점은 6점이었다. 본 연구에서 내적합치도 (Cronbach's $\alpha$ )는 .82 이었다.

\section{실행기능}

실행기능의 세 하위 요인인 억제, 작업기억, 전환을 각각 측정 하기 위해 다음과 같은 도구를 사용하였다.

억제 억제는 Gerstadt, Hong과 Diamond (1994)의 낮/밤 과제 (day-night task)와 Rueda 등(2004)이 제시한 플랭커 과제(flanker task)를 본 연구자가 수정하여 사용하였다. 낮/밤 과제는 많이 사용되지만 Mahy와 Moses (2011)의 연구에서 천장효과가 보 고된 바가 있으며, 낮/밤 과제가 자동화된 우세 반응의 억제만 을 측정한다는 주장 때문에 본 연구에서는 낮/밤 과제 외에 플 랭커 과제를 사용하여 억제를 측정하였다.

(1) 낮/밤 과제 낮/밤 과제에서는 우세 반응을 억제하는 능력을 측정하기 위해 유아들에게 낮이 연상되는 그림인 해를 보고 밤, 달 그림을 보고 낮이라고 해야 한다고 하였다. 원 도 구의 구성과 동일하게 낮/밤을 무선으로 배치하여 총 16 번의 본 시행을 진행하였다. 유아들이 컴퓨터 화면에 제시된 그림 과 반대로 연상하는 것을 5번 연속으로 실패하면 과제 진행을 중지하였다. 각 시행에서 성공하면 1점, 실패하면 0 점으로 채 점하여 총점의 범위는 0-16점이었다. 본 연구에서 내적합치도 (Cronbach's $\alpha$ )는 88 이었다.

(2) 플랭커 과제 플랭커 과제는 방해 자극에 대한 주의를 억제하는 능력을 측정하는 것으로 본 연구에서는 다음과 같이 수행 방식을 수정하여 사용하였다. 우선, 시행 전에 중립 상태 에서는 목표 자극인 방향을 화살표만 제시하고 키를 누르지 않 도록 하였다. 다음으로, 노트북 화면에 나타난 다섯 마리 물고 기의 방향이 모두 같으면 일치 조건, 이와 반대로 목표 자극인 정중앙의 물고기(예: 좌향)와 주변 물고기들(예: 우향)이 다른 방향을 가리키면 불일치 조건이었다. 일치 조건과 불일치 조건
에서는 목표 자극과 동일한 방향의 키를 오른쪽 또는 왼쪽으 로 누르도록 하였다. 특히, 불일치 조건에서는 목표 자극이 아 닌 주변 자극 방향으로 버튼을 누르면 오답으로 처리하였다.

두 번의 중립 시행을 포함하여 일치 조건을 8 회, 불일치 조 건을 8회 시행하였다. 목표 자극과 동일한 방향의 버튼을 눌렀 을 경우 1 점, 그렇지 않을 경우 0 점으로 채점하여 총점의 범위 는 0-16점이었다. 본 연구에서 내적합치도(Cronbach's $\alpha$ )는 .90 이었다.

작업기억 작업기억은 한국판 웩슬러 아동용 지능검사 4판 (Korean-Wechsler Intelligence Scale for Children-Fourth Edition [K-WISC-IV]; Kwak, Oh, \& Kim, 2011)과 Marcovitch, Boseovski, Knapp과 Kane (2010)의 도구를 참고하여 본 연구자가 구성한 숫자 거꾸로 따라하기로 측정하였다. 웩슬러 지능검사의 경우 만 6세부터 실시 가능한 도구였고 6명의 유아에게 예비실험을 실시한 결과 Marcovitch 등(2010)의 도구보다 더 저조한 수행을 보였다. 따라서, 만 4세에게 실시 가능한 Marcovitch 등(2010)의 도구를 사용하여 난이도를 조정한 뒤 2-5단위로 수정한 거꾸 로 따라하기를 본 연구에서 사용하였다.

우선 유아들은 연구자가 불러주는 여러 단위의 숫자를 듣 고 역순으로 따라하도록 연습하였다. 연습 수행으로 숫자 2 단 위(두 개)를 두 번 수행하여 유아들이 제대로 실행할 수 있는 지 확인하였다. 본 수행에서는 숫자 2 단위를 3 회 거꾸로 따라 하는 것으로 시작하여 모두 성공하면 숫자의 개수를 하나씩 늘려갔다. 최대 5 단위까지 있었으나 5 단위를 거꾸로 따라하 는 것에 성공한 유아는 없었고 최대 4 단위까지 실시하였다. 숫자 2 단위에서 4 단위까지 3회씩 9회를 실시하였고 성공할 때마다 1점을 부여하였다. 본 수행에서 유아들이 받은 최고점 은 7점이었다. 연속 세 번 실패하면 과제를 중단하였다. 내적 합치도(Cronbach's $\alpha$ )는 86 이었다.

전환 Zelazo (2006)의 차원 변경 카드 분류(Dimensional Change Card Sort [DCCS])로 전환 능력을 측정하였다. 차원 변경 카드 분류 과제는 색을 기준으로 카드를 분류하다가 기준을 모양으 로 변경하였을 때, 바뀐 기준으로 오류 없이 분류하는 것이 가 능한지 확인하는 과제였다. 유아들에게 컴퓨터 화면을 통해 상 단 중앙에 빨간 토끼, 파란 토끼, 빨간 배, 파란 배 중 한 개의 카 드가 나타나고, 화면 좌측 하단에는 파란색 토끼 박스, 우측 하 단에는 빨간색 배 박스가 나타나는 것을 보여주었다.

수행은 기본 단계와 테두리 단계로 구분되었는데 기본 단 계란 일반적인 카드를 제시하여 처음에는 색, 그 다음에는 모 
양을 기준으로 분류하는 단계였다. 테두리 단계에서는 그림 카드에 테두리가 나타나는 경우에는 색으로, 테두리가 없는 경우에는 모양을 기준으로 분류하도록 하였다. 연습 수행에서 유아가 화면 하단의 박스에 해당하는 키를 제대로 누를 수 있 는지 확인하고, 기본 단계는 색을 기준으로 6 회, 모양을 기준 으로 6 회의 총 12 회를 실시하였다. 또한 원 도구에서와 동일 하게 테두리 단계는 총 12 회를 실시하였는데 기본 단계에서 각 4회 이상 성공한 경우에만 테두리 단계를 진행하였다. 각 회를 성공한 경우 1점을 주었고, 기본과 테두리 단계를 합하여 총 24회 수행하였으므로 점수의 범위는 0-24점이었다. 내적합 치도(Cronbach's $\alpha$ )는 .92 이었다.

\section{연구절차}

본 연구에서는 측정 도구의 타당도를 확인하기 위해 연구자가 번역한 미래계획기억과 실행기능 과제를 대학원생 2 인과 아 동발달 전문가 1 인이 안면타당도를 확인하였다. 또한 4,5 세 각 3 명씩 총 6 명의 유아에게 예비실험을 실시하여 측정도구 의 난이도와 이해 수준에 오류가 없는지 점검하였다.

연구에 참여하기로 한 유아의 기관을 방문하여 총 2 회 만나 면대면으로 과제를 수행하였다. 과제 중 억제와 전환 과제는 OpenSesame 3.2.6으로 제작한 컴퓨터 기반 과제로 실시하여 오류를 최소화하였고 작업기억 과제는 구두로 진행하였다. 전 체 과제의 수가 6 개였고 유아들이 이를 하루에 수행하기는 불 가능하였으므로 이틀에 걸쳐 인터뷰를 실시하였다. 각 도구의 수행 시간을 계산하여 하루에 15 분을 넘지 않도록 도구를 세
가지씩 나누고 특히 종속변인인 미래계획기억 과제들과 두 개 의 억제과제는 한 개씩 다른 날에 수행하였다. 1 회차에서 유아 를 처음 만났을 때, 상호작용 하면서 라포를 형성한 후, 미래계 획기억 중 단어형 과제와 실행기능 중 플랭커, 차원 변경 카드 분류를 실시하였다. 2 회차에서는 범주형 미래계획기억 과제 와 낮/밤 과제, 숫자 거꾸로 따라하기 과제를 실시하였다. 각 회차마다 모든 유아에게 동일한 도구들이 실시되었고 미래계 획기억 과제를 먼저 실시하였다. 다음으로, 실행기능 과제들 의 실시 순서는 무선으로 할당하였다. 1 회차와 2 회차를 합한 전체 실험 과정은 유아 한 명 당 약 20-30분 정도 소요되었다. 모든 과제를 완료한 뒤 유아에게 보상으로 스티커를 주었다.

\section{자료분석}

연구문제 1 의 분석을 위해 $t$-test를 실시하여 연령차를 알아보 았다. 다음으로 연구문제 2 와 3 을 검정하기 위해 전체 변인들 간의 관계를 Pearson 적률상관분석을 통해 알아보고 단어형과 범주형 미래계획기억 각각에 대해 세 가지 실행기능의 하위 요인을 예측변인으로 한 단계적 회귀분석을 실시하였다. 분석 에는 SPSS 25.0 (IBM Co., Armonk, NY)를 사용하였다.

\section{Results}

\section{미래계획기억과 실행기능에서의 연령차}

Table 1 은 주요 변인들의 연령별 평균과 표준편차, $t$-test 결과

Table 1

Means and Standard Deviations of All Variables

\begin{tabular}{|c|c|c|c|c|c|c|c|}
\hline \multirow[b]{2}{*}{ Variables } & \multicolumn{2}{|c|}{$\begin{array}{l}\text { 4-year-old } \\
(n=25)\end{array}$} & \multicolumn{2}{|c|}{$\begin{array}{c}\text { 5-year-old } \\
(n=22)\end{array}$} & \multicolumn{2}{|c|}{$\begin{array}{l}\text { Total } \\
(N=47)\end{array}$} & \multirow[b]{2}{*}{$t$-test } \\
\hline & $M$ & $S D$ & $M$ & $S D$ & $M$ & $S D$ & \\
\hline Inhibition & 22.56 & 5.55 & 28.86 & 5.53 & 27.64 & 5.60 & -1.42 \\
\hline Flanker task & 13.72 & 3.59 & 14.64 & 2.72 & 14.15 & 3.21 & -.99 \\
\hline Shifting (DCCS) & 13.24 & 6.82 & 16.36 & 4.86 & 14.70 & 6.13 & -1.79 \\
\hline Prospective memory & 4.92 & 4.24 & 7.86 & 3.15 & 6.30 & 4.02 & $-2.67^{*}$ \\
\hline Word-based task & 3.12 & 2.79 & 5.32 & 1.76 & 4.15 & 2.59 & $-3.18^{* *}$ \\
\hline Category-based task & 1.80 & 2.00 & 2.55 & 1.97 & 2.15 & 2.00 & -1.28 \\
\hline
\end{tabular}

Note. BDS = backward digit span; DCCS = dimensional change card sort.

${ }^{*} p<.05 .{ }^{* *} p<.01$. 
를 보여주고 있다. Table 1을 살펴보면, 만 4세 유아보다 만 5세 유아들이 몇몇 부분에서 더 높은 수행을 보였다. 연령차를 알 아본 결과, 단어형 과제 $(t=-3.18, d f=45, p<.01)$ 에서 만 5 세가 만 4세보다 미래계획기억을 더 잘 수행하는 것으로 나타났다. 그러나 범주형 과제에서는 연령차가 나타나지 않았으며 실행 기능의 세 가지 하위 요인 중 작업기억에서만 5 세의 수행이 유 의하게 높았다 $(t=-3.51, d f=45, p<.01)$. 이처럼 연령차가 각 변인의 하위 요인 중 한 개씩에서만 유의하였고 나머지 요인 에서는 유의하지 않았으며, 각 연령별로 다변량 분석을 수행 하기에 파워가 충분하지 않았으므로 이후 분석은 전체 유아를 대상으로 실시하였다.

\section{유아의 실행기능이 단어형 미래계획기억 과제 수행에 미치는 영향}

Table 2는 모든 연구 변인들 간의 상관 분석 결과를 보여준다. Table 2 를 살펴보면, 유아의 단어형 미래계획기억은 억제 $(r=$ $.47, p<.01)$ 및 작업기억 $(r=.39, p<.01)$ 과 정적 상관이 유의 하였다. 단어형 미래계획기억과 억제의 상관을 과제별로 살 펴보면, 플랭커 과제 $(r=.41, p<.01)$ 와 낮/밤 과제 $(r=.39, p<$
.01) 모두에서 각각 유의한 정적 상관을 보였다. 즉, 유아의 억 제 능력이 높을수록 단어형 과제에서 미래계획기억 수행을 잘 하는 것으로 나타났다. 또한 작업기억은 단어형 미래계획기억 과 유의한 정적 상관이 있었으나 $(r=.39, p<.01)$ 전환과 미래 계획기억과의 상관은 유의하지 않았다.

다음으로, 실행기능이 단어형 미래계획기억 과제 수행에 미치는 영향을 알아보기 위해 실시한 단계적 회귀분석 결과 가 Table 3에 제시되어있다. 회귀분석을 수행하기 위해 플랭커 과제와 낮/밤 과제의 점수를 합산한 억제 총점을 사용하였다. 단계적 회귀분석 모형은 Durbin-Watson 지수가 2.18 로 잔차의 독립성 가정이 충족되었고 VIF값은 1.08 로 다중공선성이 없 는 것으로 나타났다. Table 3 을 살펴보면, 억제 $(\beta=.39, p<.01)$ 와 작업기억 $(\beta=.28, p<.05)$ 이 단어형 미래계획기억에 유의 하게 영향을 미치는 것으로 나타났으며, 전환의 영향은 유의 하지 않았다. 이 회귀 모델은 전체 변량의 $30 \%$ 를 설명하였다.

\section{유아의 실행기능이 범주형 미래계획기억 과제 수행에 미치는 영향}

다음으로 Table 2에서 실행기능과 범주형 미래계획기억과의

Table 2

Correlations Among Variables

$\begin{array}{llllll}1 & 2 & 3 & 4 & 5 & 6\end{array}$

Executive function

1. Inhibition

2. Flanker

3. Day/night

4. Working memory

5. Shifting

$-82^{* * *}$
$.85^{* * *}$
.28
$40^{* *}$

$.39^{* *}$

.08

$.29 *$

$.47^{* *}$

$.30^{*}$

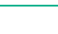

Prospective memory

\begin{tabular}{|c|c|c|c|c|c|c|}
\hline 6. Word-based task & $.47^{* *}$ & $.41^{* *}$ & $.39^{* *}$ & $.39^{* *}$ & .20 & - \\
\hline 7. Category-based task & $.30^{*}$ & $.29^{*}$ & .22 & .24 & .12 & $.53^{* * *}$ \\
\hline
\end{tabular}

Note. $N=47$. Inhibition = flanker+day/night; Working memory = backward digit span; Shifting = dimensional change card sort.

${ }^{*} p<.05 .{ }^{* *} p<.01 .{ }^{* * *} p<.001$.

Table 3

Multiple Regression Analyses of the Influence of Executive Function on Prospective Memory

\begin{tabular}{llllll}
\hline \multicolumn{1}{c}{ Criterion variables } & \multicolumn{1}{c}{ Predictor variables } & $B$ & $\beta$ & $t$ & $R^{2}$ \\
\hline Word-based PM & Inhibition & .18 & .39 & $3.00^{* *}$ & .30 \\
& Working memory & .31 & .28 & $2.16^{*}$ & $9.34^{* * *}$ \\
Category-based PM & Inhibition & .11 & .30 & $2.14^{*}$ & .09 \\
\hline
\end{tabular}

Note. $N=47 . \mathrm{PM}=$ prospective memory; Inhibition = flanker+day/night; Working memory = backward digit span.

${ }^{*} p<.05 .{ }^{* *} p<.01 .{ }^{* * *} p<.001$. 
상관을 알아본 결과, 범주형 과제는 억제 중에서 플랭커 과제 $(r=.29, p<.05)$ 와 유의한 정적 상관을 보였으나 낮/밤 과제와 의 상관은 유의하지 않았다. 또한 작업기억과 전환은 범주형 과제의 수행과 유의한 관련성이 없었다.

범주형 미래계획기억을 종속 변인으로 하여 단계적 회귀분 석을 실시한 모형의 Durbin-Watson 지수는 1.92 , VIF값은 1.0 으로 나타났다. 위의 Table 3을 보면 실행기능의 세 하위 요인 중 억제 $(\beta=.30, p<.05)$ 만 범주형 미래계획기억에 정적 영향 을 미치고 있었으며 작업기억이나 전환의 영향은 유의하지 않 았다. 즉, 범주형 미래계획기억의 경우 억제가 가장 주요하게 설명하는 변인이었으며 이 회귀 모델은 전체 변량의 $9 \%$ 를 설 명하였다.

\section{Discussion}

본 연구에서는 만 4,5 세 유아의 미래계획기억과 실행기능 간 의 관계를 검정하였다. 사건 기반 미래계획기억을 단어형과 범주형 과제로 측정하고 실행기능의 영향을 알아보았다. 연구 결과는 다음과 같다.

첫째, 만 5세 유아들의 미래계획기억 과제 수행 평균이 만 4세 유아보다 대체로 높았으나 단어형 과제에서만 연령 간의 차이가 통계적으로 유의한 것으로 나타났다. 반면, 범주형 미 래계획기억에서는 유의한 연령차가 나타나지 않았다. 유아들 은 단어형보다 범주형 과제에서 낮은 수행을 보이긴 했지만, 범주형 과제도 어느 정도 수행할 수 있었다.

유아기는 Piaget의 전조작기에 해당하는 시기로 표상과 개 념의 발달이 급격하게 일어난다. 또한 만 4 세 이후부터는 어휘 와 개념의 이해가 크게 증가하고, 지속적인 학습을 통하여 유 아들의 범주화 능력을 향상시킬 수 있다(Callanan, 1989; H. J. $\mathrm{Kim}, 2000)$. 그러나 보존이나 유목 분류와 같은 보다 상위의 인지는 구체적 조작기가 되어야 획득한다고 알려졌다. 본 연 구에서는 범주형 과제를 수행한 만 4세 유아들이 있었고, 이는 전조작기에도 유목 분류에 대한 이해가 가능하다는 것을 제시 한다. 즉, Piaget가 제시한 단계보다 더 빨리 인지적 과제의 수 행이 가능하다는 것을 보여준다.

한편, 미래계획기억의 발달에서 만 3-5세 간에 연령차가 없 었던 Seo와 Choi (2004)의 연구와는 달리, 본 연구에서는 만 4 세와 5세 간에 연령차가 유의하였다. 이러한 결과는 미래계획 기억을 측정하는 과제에 따라 다른 발달적 차이를 보여주었 던 선행 연구들(Guajardo \& Best, 2000; Walsh et al., 2014)을 지
지하는 결과이다. 본 연구에서 단순 미래계획기억 과제의 수 행을 살펴보면, 6 점 만점 중 만 5세는 평균 5.32점을 나타낸 반 면, 만 4세는 평균 3.12점으로 4세와 5 세의 차이가 유의한 것 을 볼 수 있다. 유목이 포함된 범주형 과제에서는 만 4 세와 5 세의 수행에 유의한 차이가 없었다. 그러나, 유아의 개인차가 있었는데 만 5세 중에서 점수를 획득하지 못하는 유아들이 있 었던 반면, 만점을 획득하며 뛰어난 수행을 보이는 만 4세 유 아들도 있었다. 더불어, 연령과 관계없이 연구에 참여한 유아 중 약 삼분의 이에 해당하는 유아들이 범주형 과제를 수행하 는 것이 가능하였다. 이를 미루어볼 때, 만 4-5세에는 인지적 상위개념이 발달하는 중이라고 생각할 수 있다. 복잡한 인지 과제를 기반으로 한 미래계획기억은 유아들의 인지 능력이 발 달하면서 같이 증가할 것으로 생각되며 연령적 추이는 향후 더 넓은 연령집단을 대상으로 확인할 필요가 있을 것이다.

둘째로, 유아의 실행기능이 미래계획기억에 미치는 영향을 살펴본 결과, 전반적으로 실행기능의 세 요인 중에서 억제와 작업기억이 미래계획기억에 유의한 영향을 미치는 것으로 나 타났다. 억제를 잘 하는 유아일수록 단어형과 범주형 미래계 획기억 과제 수행이 모두 높았으며 작업기억은 단어형 미래계 획기억에 정적으로 영향을 미쳤다. 실행기능의 억제와 미래계 획기억의 관계는 여러 선행 연구들(Causey \& Bjorklund, 2014; Ford et al., 2012; Mahy et al., 2014)에서 찾아볼 수 있다. 억제가 미래계획기억에 영향을 미치는 이유는, 미래계획기억이 현재 자극에 대한 주의를 잠시 철회하고 이전에 기억하던 단서를 회상하는 것이기 때문이다(Wang, Kliegel, Liu, \& Yang, 2008). 다시 말해, 미래계획기억 단서와 연결된 목표 행동을 기억하 고 있더라도 계속 해오던 행동을 억제하고 중단하지 못하면 목표 행동을 수행할 수 없다. 이러한 점에서 억제가 미래계획 기억에 중요한 영향을 미쳤을 것으로 생각된다.

무엇보다, 본 연구에서는 억제를 측정하는 과제에 따라 미 래계획기억과의 관계에 차이가 있었다. 단어형 미래계획기억 에서는 차이가 없었으나 범주형 미래계획기억과의 관계는 플 랭커 과제를 사용한 경우에만 유의한 상관이 나타났다. 두 과 제는 모두 억제를 측정할 때 가장 보편적으로 쓰이는데 낮/ 밤 과제는 우세 반응을 억제하는 능력을 측정(Montgomery \& Koeltzow, 2010)하는 반면, 플랭커 과제는 목표 자극과 방해 자 극이 한 화면에 함께 노출되기 때문에, 방해 자극에 대한 간섭 을 조절하여야 목표 자극에 주의를 기울일 수 있다. 다시 말해, 플랭커 과제는 인지적 자원의 할당이 낮/밤 과제보다 더 요구 되는 형태이므로 이러한 점이 범주형 미래계획기억에 영향을 주었을 것으로 생각된다. 범주형 미래계획기억 과제가 플랭커 
와 유사하게 간섭과 주의의 분배가 더 요구되는 형태이기 때 문이다.

마지막으로, 본 연구에서 유아의 작업기억이 미래계획기억 에 미치는 영향은 사건 기반 기억과 작업기억 간의 관계를 밝 힌 Mahy와 Moses (2011)의 연구 결과를 지지한다. 미래계획기 억 과제를 수행할 때, 작업기억의 기본적인 역할은 목표 단서 의 출현을 모니터링하면서 단서와 연결된 규칙이나 계획을 머 릿속에 유지하는 것이다(Spiess, Meier, \& Roebers, 2016). 작업 기억은 과제와 관련된 정보를 의식적으로 조작하는 과정에 관 여하기 때문에 단순히 과제와 관련된 정보의 저장을 넘어 정 보를 선택하고 통합하는 역할을 수행한다(Voigt et al., 2014).

본 연구에서 유아의 작업기억은 단어형 과제와 범주형 과 제에 각각 다른 영향을 미쳤다. 이는 작업기억의 중앙실행기 에 과부하가 걸리는 경우 미래계획기억 과제 수행 능력이 저 하된다고 보고한 Marsh와 Hicks (1998)의 연구와 유사하다. Baddeley (2012)에 따르면 중앙실행기는 과제에 주의를 집중 하고 필요한 용량을 분배하여 과제 간 이동이 용이하도록 하 는 감독계획자 역할을 한다. 만 4,5 세 유아들은 난이도가 높 은 범주형 과제를 수행할 때 중앙실행기에 과부하가 발생하게 되는데, 미래계획기억 과제를 수행하기 위해서는 주의를 잘 통제하여 목표 단서를 범주화하여야 하기 때문이다. 그러나 유아기에는 작업기억 능력이 충분히 발달하지 않아 인지적 자 원의 조절에 어려움이 발생하고, 결과적으로 범주형 미래계획 기억 과제 수행이 전체적으로 어려울 수 있다. 반면, 난이도가 높지 않은 단어형 과제 수행은 작업기억 능력 범위에 따라 영 향을 받는 것으로 생각된다.

종합하면, 본 연구를 통해 실행기능의 하위 요인이 유아 의 미래계획기억에 다른 영향을 미치는 것을 알 수 있었고, 이 는 실행기능 요인의 발달 양상에 차이가 있음을 보여준다. 예 를 들어, 억제는 만 3세에서 4세경에 출현하여 8세까지 지속 적으로 발달하는 것으로 알려져 있다(Best \& Miller, 2010). 반 면, 주의에 영향을 많이 받는 작업기억은 망상계가 발달하는 청소년기까지 발달하기 때문에 유아기와 아동기 동안 다소 느 리게 발달하는 경향이 있다(Gathercole, Pickering, Ambridge, \& Wearing, 2004; van't Wout et al., 2019). 마지막으로 전환은 억 제와 작업기억을 복합적으로 활용해야 하기 때문에 역시 청 소년기 이후까지 발달하는 것으로 보고되고 있다(Huizinga, Dolan, \& van der Molen, 2006).

이렇게 실행기능 하위 요인의 발달적 차이가 미래계획기 억에 영향을 주었을 가능성이 있다. 특히, 본 연구에서는 전환 이 미래계획기억과 유의한 관계를 나타내지 않았는데 전환 과
제의 수행을 위해서는 억제와 작업기억이 충분히 발달되어야 한다고 알려져 있으며 세 하위 요인 중에서는 가장 늦게 발달 하는 것으로 보고되고 있다(Garon, Bryson, \& Smith, 2008). 본 연구결과는 전환과 미래계획기억 간의 유의한 관계를 보고한 Causey와 Bjorklund (2014)의 결과와는 일치하지 않지만, 이 외 에 다른 선행 연구들(Mahy et al., 2014; Mäntylä et al., 2007)에 서는 본 연구에서처럼 전환의 영향이 유의하지 않았다. 따라 서 전환과 관련된 연구들의 불일치에 대해서는 이후 다시 알 아볼 필요가 있을 것이다.

이 외에 다음과 같은 점이 이후 연구에서 더 고려되어야 할 것으로 생각된다. 우선, 본 연구에서는 유아들에게 친숙한 사 건 기반 미래계획기억에 집중하였으나 후속 연구에서는 시간 기반 미래계획기억을 다룬 선행 연구들(Aberle \& Kliegel, 2010; Voigt et al., 2014)을 참고하여 다양한 형태의 미래계획기억 수 행을 알아볼 필요가 있다. 특히, 후속 연구에서는 미래계획기 억 과제들 간에 비교 가능한 실험설계를 적용하여 연구 결과의 차이가 과제의 특성에서 기인한 것인지 발달적 특성에 영향을 받은 것인지 검증하는 것도 의미가 있을 것이다. 다음으로, 본 연구에서 실행기능의 세 요소인 억제, 작업기억, 전환만 다루 었지만 주의나 과제 수행 책략 역시 실행기능의 요소로 꼽히고 있다. 과제 수행 동기 등도 주요한 요소이다. 따라서 이후 연구 에서는 현재 고려하지 않은 실행기능의 요소들을 더 고려할 필 요가 있다. 마지막으로, 본 연구에서는 억제를 측정하는 도구 두 가지를 사용한 반면, 다른 요인들은 한 가지 과제로 측정하 였다. 작업기억과 전환 역시 다른 과제로 측정한 경우 연구 결 과에 차이가 날 수 있으므로 추후 미래계획기억과의 관계를 연 구할 때는 다양한 형태의 실행기능 측정 도구를 고려하여 도구 간 비교를 더 상세히 제시할 필요가 있을 것이다.

\section{Notes}

This article is a part of the first author's master's thesis submitted in 2019 .

\section{Conflict of Interest}

No potential conflict of interest relevant to this article was reported. 


\section{References}

\section{In English}

Aberle, I., \& Kliegel, M. (2010). Time-based prospective memory performance in young children. European Journal of Developmental Psychology, 7(4), 419-431. doi:10.1080/1740 5620802507707

Anderson, P. (2002). Assessment and development of Executive Function (EF) during childhood. Child Neuropsychology, 8(2), 71-82. doi:10.1076/chin.8.2.71.8724

Aron, A. R., Robbins, T. W., \& Poldrack, R. A. (2014). Inhibition and the right inferior frontal cortex: One decade on. Trends in Cognitive Sciences, 18(4), 177-185. doi:10.1016/ j.tics.2013.12.003

Baddeley, A. (2012). Working memory: Theories, models, and controversies. Annual Review of Psychology, 63, 1-29. doi:10.1146/annurev-psych-120710-100422

Barbey, A. K., Koenigs, M., \& Grafman, J. (2013). Dorsolateral prefrontal contributions to human working memory. Cortex, 49(5), 1195-1205. doi:10.1016/j.cortex.2012.05.022

Best, J. R., \& Miller, P. H. (2010). A developmental perspective on executive function. Child Development, 81(6), 1641-1660. doi:10.1111/j.1467-8624.2010.01499.x

Bjorklund, D. F., \& Causey, K. B. (2017). Children's thinking: Cognitive development and individual differences (6th ed.). Thousand Oaks, CA: Sage Publications.

Callanan, M. A. (1989). Development of object categories and inclusion relations: Preschoolers' hypotheses about word meanings. Developmental Psychology, 25(2), 207-216. doi:10.1037/0012-1649.25.2.207

Carlson, S. M. (2003). Executive function in context: Development, measurement, theory, and experience. Monographs of the Society for Research in Child Development, 68(3), 138-151. doi:10.1111/j.1540-5834.2003.06803012.x

Carlson, S. M. (2005). Developmentally sensitive measures of executive function in preschool children. Developmental Neuropsychology, 28(2), 595-616. doi:10.1207/s1532694 2dn2802_3

Causey, K. B., \& Bjorklund, D. F. (2014). Prospective memory in preschool children: Influences of agency, incentive, and underlying cognitive mechanisms. Journal of Experimental Child Psychology, 127, 36-51. doi:10.1016/j.jecp.2014.01.020

Clark, J. M., \& Johnson, C. J. (1994). Retrieval mechanisms in the development of instance and superordinate naming of pictures. Journal of Experimental Child Psychology, 57(3), 295-326. doi:10.1006/jecp.1994.1015

Diamond, A. (2013). Executive functions. Annual Review of Psychology, 64, 135-168. doi:10.1146/annurev-psych-113011-143750
Einstein, G. O., \& McDaniel, M. A. (1990). Normal aging and prospective memory. Journal of Experimental Psychology: Learning, Memory, and Cognition, 16(4), 717-726. doi:10.1037/0278-7393.16.4.717

Ellis, J., \& Kvavilashvili, L. (2000). Prospective memory in 2000: Past, present, and future directions. Applied Cognitive Psychology, 14(7), S1-S9. doi:10.1002/acp.767

Ford, R. M., Driscoll, T., Shum, D., \& Macaulay, C. E. (2012). Executive and theory-of-mind contributions to event-based prospective memory in children: Exploring the self-projection hypothesis. Journal of Experimental Child Psychology, 111(3), 468-489. doi:10.1016/j.jecp.2011.10.006

Friedman, N. P., \& Miyake, A. (2017). Unity and diversity of executive functions: Individual differences as a window on cognitive structure. Cortex, 86, 186-204. doi:10.1016/ j.cortex.2016.04.023

Garon, N., Bryson, S. E., \& Smith, I. M. (2008). Executive function in preschoolers: A review using an integrative framework. Psychological Bulletin, 134(1), 31-60. doi:10.1037/00332909.134.1.31

Gathercole, S. E., Pickering, S. J., Ambridge, B., \& Wearing, H. (2004). The structure of working memory from 4 to 15 years of age. Developmental Psychology, 40(2), 177-190. doi:10.1037/0012-1649.40.2.177

Gerstadt, C. L., Hong, Y. J., \& Diamond, A. (1994). The relationship between cognition and action: Performance of children $3 \frac{1}{2-2}-7$ years old on a stroop-like day-night test. Cognition, 53(2), 129-153. doi:10.1016/00100277(94)90068-X

Gomez, R., Gomez, R. M., Winther, J., \& Vance, A. (2014). Latent profile analysis of working memory performance in a sample of children with ADHD. Journal of Abnormal Child Psychology, 42(8), 1367-1379. doi:10.1007/s10802014-9878-5

Guajardo, N. R., \& Best, D. L. (2000). Do preschoolers remember what to do? Incentive and external cues in prospective memory. Cognitive Development, 15(1), 75-97. doi:10.1016/ S0885-2014(00)00016-2

Huizinga, M., Dolan, C. V., \& van der Molen, M. W. (2006). Agerelated change in executive function: Developmental trends and a latent variable analysis. Neuropsychologia, 44(11), 2017-2036. doi:10.1016/j.neuropsychologia.2006.01.010

Josselyn, S. A., \& Frankland, P. W. (2012). Infantile amnesia: A neurogenic hypothesis. Learning \& Memory, 19(9), 423433. doi: $10.1101 / \mathrm{lm} .021311 .110$

Kim, C., Johnson, N. F., Cilles, S. E., \& Gold, B. T. (2011). Common and distinct mechanisms of cognitive flexibility in prefrontal cortex. The Journal of Neuroscience, 31(13), 4771-4779. doi:10.1523/JNEUROSCI.5923-10.2011

Kliegel, M., \& Jäger, T. (2007). The effects of age and cue-action 
reminders on event-based prospective memory performance in preschoolers. Cognitive Development, 22(1), 33-46. doi:10.1016/j.cogdev.2006.08.003

Leigh, J., \& Marcovitch, S. (2014). The cognitive cost of event-based prospective memory in children. Journal of Experimental Child Psychology, 127, 24-35. doi:10.1016/j.jecp.2014.02.010

Lourenço, O., \& Machado, A. (1996). In defense of Piaget's theory: A reply to 10 common criticisms. Psychological Review, 103(1), 143-164. doi:10.1037/0033-295X.103.1.143

Lucariello, J., Kyratzis, A., \& Nelson, K. (1992). Taxonomic knowledge: What kind and when? Child Development, 63(4), 978-998. doi:10.1111/j.1467-8624.1992.tb01676.x

Mahy, C. E. V., \& Moses, L. J. (2011). Executive functioning and prospective memory in young children. Cognitive Development, 26(3), 269-281. doi:10.1016/j.cogdev.2011. 06.002

Mahy, C. E. V., Moses, L. J., \& Kliegel, M. (2014). The impact of age, ongoing task difficulty, and cue salience on preschoolers' prospective memory performance: The role of executive function. Journal of Experimental Child Psychology, 127, 52-64. doi:10.1016/j.jecp.2014.01.006

Mäntylä, T., Carelli, M. G., \& Forman, H. (2007). Time monitoring and executive functioning in children and adults. Journal of Experimental Child Psychology, 96(1), 1-19. doi:10.1016/j.jecp.2006.08.003

Marcovitch, S., Boseovski, J. J., Knapp, R. J., \& Kane, M. J. (2010). Goal neglect and working memory capacity in 4- to 6-yearold children. Child Development, 81(6), 1687-1695. doi:10.1111/j.1467-8624.2010.01503.x

Marsh, R. L., \& Hicks, J. L. (1998). Event-based prospective memory and executive control of working memory. Journal of Experimental Psychology: Learning, Memory, and Cognition, 24(2), 336-349. doi:10.1037/0278-7393.24.2.336

McDaniel, M. A., \& Einstein, G. O. (2000). Strategic and automatic processes in prospective memory retrieval: A multiprocess framework. Applied Cognitive Psychology, 14(7), S127-S144. doi:10.1002/acp.775

McDaniel, M. A., LaMontagne, P., Beck, S. M., Scullin, M. K., \& Braver, T. S. (2013). Dissociable neural routes to successful prospective memory. Psychological Science, 24(9), 17911800. doi: $10.1177 / 0956797613481233$

Miyake, A., Friedman, N. P., Emerson, M. J., Witzki, A. H., Howerter, A., \& Wager, T. D. (2000). The unity and diversity of executive functions and their contributions to complex "frontal lobe" tasks: A latent variable analysis. Cognitive Psychology, 41(1), 49-100. doi:10.1006/ cogp.1999.0734

Montgomery, D. E., \& Koeltzow, T. E. (2010). A review of the day-night task: The stroop paradigm and interference control in young children. Developmental Review, 30(3),
308-330. doi:10.1016/j.dr.2010.07.001

Rueda, M. R., Fan, J., McCandliss, B. D., Halparin, J. D., Gruber, D. B., Lercari, L. P., \& Posner, M. I. (2004). Development of attentional networks in childhood. Neuropsychologia, 42(8), 1029-1040. doi:10.1016/j.neuropsychologia. 2003.12.012

Ślusarczyk, E., Niedźwieńska, A., \& Białecka-Pikul, M. (2018). The first signs of prospective memory. Memory, 26(10), 1385-1395. doi:10.1080/09658211.2018.1483516

Smidts, D. P., Jacobs, R., \& Anderson, V. (2004). The Object Classification Task for Children (OCTC): A measure of concept generation and mental flexibility in early childhood. Developmental Neuropsychology, 26(1), 385-401. doi:10.1207/s15326942dn2601_2

Smith, R. E. (2003). The cost of remembering to remember in event-based prospective memory: Investigating the capacity demands of delayed intention performance. Journal of Experimental Psychology: Learning, Memory, and Cognition, 29(3), 347-361. doi:10.1037/0278-7393.29.3.347

Somerville, S. C., Wellman, H. M., \& Cultice, J. C. (1983). Young children's deliberate reminding. The Journal of Genetic Psychology, 143(1), 87-96. doi:10.1080/00221325.1983.10 533537

Spiess, M. A., Meier, B., \& Roebers, C. M. (2016). Development and longitudinal relationships between children's executive functions, prospective memory, and metacognition. Cognitive Development, 38, 99-113. doi:10.1016/j.cogdev. 2016.02.003

Sutherland, R., Pipe, M.-E., Schick, K., Murray, J., \& Gobbo, C. (2003). Knowing in advance: The impact of prior event information on memory and event knowledge. Journal of Experimental Child Psychology, 84(3), 244-263. doi:10.1016/S0022-0965(03)00021-3

van't Wout, F., O’Donnell, M., \& Jarrold, C. (2019). An investigation of children's working memory capacity for task rules. Cognitive Development, 51, 14-31. doi:10.1016/ j.cogdev.2019.05.007

Voigt, B., Mahy, C. E. V., Ellis, J., Schnitzspahn, K., Krause, I., Altgassen, M., \& Kliegel, M. (2014). The development of time-based prospective memory in childhood: The role of working memory updating. Developmental Psychology, 50(10), 2393-2404. doi:10.1037/a0037491

Walsh, S. J., Martin, G. M., \& Courage, M. L. (2014). The development of prospective memory in preschool children using naturalistic tasks. Journal of Experimental Child Psychology, 127, 8-23. doi:10.1016/j.jecp.2013.10.003

Wang, L., Kliegel, M., Liu, W., \& Yang, Z. (2008). Prospective memory performance in preschoolers: Inhibitory control matters. European Journal of Developmental Psychology, 5(3), 289-302. doi:10.1080/17405620600778161 
Winer, G. A. (1980). Class-inclusion reasoning in children: A review of the empirical literature. Child Development, 51(2), 309-328. doi:10.2307/1129264

Zelazo, P. D. (2006). The Dimensional Change Card Sort (DCCS): A method of assessing executive function in children. Nature Protocols, 1(1), 297-301. doi:10.1038/ nprot.2006.46

Zhang, X., Ballhausen, N., Liu, S., Kliegel, M., \& Wang, L. (2019). The effects of ongoing task absorption on event-based prospective memory in preschoolers. European Journal of Developmental Psychology, 16(2), 123-136. doi:10.1080/17 405629.2017.1346503

Zhang, X., Zuber, S., Liu, S., Kliegel, M., \& Wang, L. (2017). The effects of task instructor status on prospective memory performance in preschoolers. European Journal of Developmental Psychology, 14(1), 102-117. doi:10.1080/17 405629.2016.1165660

\section{In Korean}

Jeun, D. I., \& Kang, Y. (2007). Category norms of Korean for elementary school children. Communication Science \& Disorders, 12(1), 90-104.

Kang, Y. (2003). A normative study of the Seoul Verbal Learning Test-Children's version (SVLT-C). The Korean Journal of
Clinical Psychology, 22(2), 435-448.

Kim, H. J. (2000). The effects of cognitive apprenticeship on categorizing behavior by intelligence in kindergarten children. Korean Journal of Child Studies, 21(2), 33-44.

Kwak, K., Oh, S., \& Kim, C. (2011). Korean-Wechsler Intelligence Scale for Children-Fourth edition (K-WISC-IV). Seoul: Insight of Psychology.

Seo, J.-Y., \& Choi, K.-S. (2004). The development of children's prospective memory: A comparison of the performance with time-based and event-based task. The Korean Journal of the Human Development, 11(1), 87-101.

\section{ORCID}

So Yeon Park http://orcid.org/0000-0002-0945-7256

Hana Song http://orcid.org/0000-0002-7745-7303

Received July 31, 2019

Revision received September 9, 2019

Accepted October 172019 